\title{
Emergence of a new method: The Grounded Delphi Method
}

\author{
Katherine Howard
}

\begin{abstract}
This paper reports on the Grounded Delphi Method (GDM), a relatively new methodological extension of the Delphi method, achieved by incorporating aspects of grounded theory, as used in a recent doctoral dissertation. The research explored the skills, knowledge, qualities, and professional education needs of information professionals in galleries, libraries, archives, and museums (GLAM) in Australia, with a view to determining relevant educational requirements to enable information professionals to operate across blurred cultural heritage boundaries. Implications of using GDM for Library and Information Science (LIS) research, and for research methods in general, is that it improves the rigour of theory building in Delphi studies, while the consensus, or force ranking, aspect of Delphi assists in improving the relevant level of importance of categories derived from grounded theory.
\end{abstract}

\section{Author}

Katherine Howard is a College and Research Services Librarian at Flinders University, Adelaide, South Australia. She assists academics and $\mathrm{PhD}$ students with their research needs, with a focus on Research Data Management training.

Email: katherine.howard@flinders.edu.au

Received 09 February 2017

Accepted 19 February 2018 


\section{Introduction}

The Grounded Delphi Method (GDM) is a relatively new addition to the research methods landscape. It was developed and first used by Päivärinta, Pekkola and Moe (2011) in a study about the challenges associated with information technology procurement in the public sector in Norway (Moe and Päivärinta, 2011). Since then it has been used in two doctoral dissertations: one in the area of business decision making in 2012; and the second in research exploring the skills, knowledge, qualities and professional education needs of information professionals in galleries, libraries, archives and museums (GLAM) in Australia in 2015, with a focus on the future education requirements of these professionals. It is the application of the GDM in the latter research that is the subject of this paper.

The GDM integrates aspects of grounded theory with the Delphi method, a group communication tool and a means to achieve consensus. The key feature of the GDM is the use of grounded theory data analysis processes that are conducted simultaneously with data collection, through the use of coding techniques. Thus, after each data collection round, data analysis generates a series of categories that form the basis for the next data collection round. By incorporating elements of grounded theory in both the data collection and data analysis phases, GDM also attempts to improve the theory building aspect of the Delphi method. Before detailing the application of GDM to the study, an overview of both the Delphi method and grounded theory will be provided, which clarifies the origins of the various elements that form the GDM. 


\section{The Delphi method}

Dalkey and Helmer of the RAND Corporation first documented the Delphi method in a paper in 1963 (Dalkey and Helmer, 1963) in which they described the method as it had been used approximately 10 years earlier "to forecast the impact of technology on warfare" (RAND Corporation, 2012, para. 1). It is this forecasting feature that gave the method its name - after the Oracle of Delphi who, according to Greek myth, made predictions and answered questions about the future.

The Delphi method is both a group communication tool and a means to achieve consensus amongst experts on a given topic (Hsu and Sandford, 2010), and is based on the idea that "the collective wisdom of a group" (Forsyth, 2010, p. 196) reduces ambiguity and increases accuracy (Forsyth, 2010). It is a highly structured approach to data collection. The process itself is iterative, involving multiple rounds of questionnaires to be completed by participants, with the results of each round informing the next. After each round, the responses are analysed by the researcher and an anonymous summary is provided to all participants, which includes the reasons and justifications as to why particular choices were made. This then allows participants in each subsequent round to review their own selections in light of other participants' choices. As such, the development of the questionnaire, the data collection and data analysis are intertwined throughout and between each round.

Depending on the objective of the study, individual Delphi rounds can be adapted accordingly to suit. For example, Linstone and Turoff (1975) discuss a Delphi study where "the overall objective was to obtain a rank ordered list" (p. 
91). In this case, participants were presented with a list of items that they were required to 'force rank' - that is, they must place each item in an ordered list of importance. However, as Delphi has also been suggested as being “most appropriate when opinions are being sought" (Charlton, 2004, p. 245), a ranking of items may not be the most suitable course of action. In these cases, which includes this dissertation research, a study is deemed to have reached consensus once responses "reach a prescribed or a priori range" (Hsu and Sandford, 2010, p. 344). In studies that use force ranking, what constitutes consensus is at the discretion of the researcher (Hsu and Sandford, 2010).

\section{The panel of experts}

The selection of participants - the so-called panel of experts - is considered the most critical aspect of a Delphi study (Hsu and Sandford, 2010). Resting on Murry and Hammons' (1995) assumption “that group decisions are usually more valid than decisions made by a single person" (p. 426), they further argue that those decisions "are more valid if the group is comprised of experts" (Murry and Hammons, 1995, p. 426).

A further matter to be considered when selecting participants is that the Delphi method can be open to bias. According to Rowe, Wright, and Bolger (1991), researchers often select participants because of the following reasons:

- they are easily available

- their reputations are known to the researcher

- they meet a minimal number of criteria regarding the field of the research problem

- the 'self-rating' of their expertise (p. 324) 
Judd (1972), in reference to setting up a panel of experts for a Delphi study in the field of higher education, cautions about what he refers to as 'inbreeding.' That is, selecting participants because they are likely to share "a singular set of judgements because of background and training” (p. 181). In order to address these issues of bias, I established criteria in terms of the level of expertise required and made requests for participation based on these criteria. This aspect is discussed in detail in the "Selecting the panel of experts: Online questionnaire rounds" section below.

No clear consensus has been reached in the literature about the ideal number of participants for a successful Delphi study. The recommended numbers vary from 5-20 (Forsyth, 2010), 15-20 (Hsu and Sandford, 2010), and 10-15 (Delbecq, Van de Ven and Gustafson, 1975). However, a balance needs to be struck - too few members may not adequately represent the varying opinions of the topic under investigation, and if a wide or divergent opinion is required, more participants will be required (Hsu and Sandford, 2010).

\section{Delphi rounds}

The number of rounds of a Delphi study is not prescriptive. Much of the literature suggests a minimum of two rounds, more usually three or four (Charlton, 2007; Hurworth, 2005; Lang, 1994, in Day and Bobeva, 2005). Errfmeyer, Erffmeyer, and Lane (1986, in Day and Bobeva, 2005) deem anything between two and 10 rounds acceptable. Gottschalk (2000) on the other hand has identified Delphi studies with only one round. 
In the first round, according to Hsu and Sandford (2010), two approaches can be taken, exploratory or confirmatory. The most traditional form of Delphi begins with an exploratory open-ended questionnaire designed to elicit thoughts and ideas from the participants. Similar in nature to a 'brainstorming' session, this approach is particularly suitable when there is limited empirical evidence available to be able to form a definitive questionnaire.

The alternative first round 'confirmatory' approach (Day and Bobeva, 2005) draws on an extensive review of the literature in order to circulate "a predefined list of issues to the panel" (Day and Bobeva, 2005, p. 106). It is particularly suited to follow-up studies where sufficient empirical data exists.

\section{Advantages and disadvantages of Delphi}

One of the major advantages of using the Delphi method is that it preserves anonymity amongst the participants. It benefits from group decisionmaking, while eliminating disadvantages of face-to-face group interactions where members may be dominated by stronger personalities, people in positions of authority or be biased because of the 'bandwagon' or 'halo' effect. Murry and Hammons (1995) claim that the "controlled-feedback procedures are often more accurate than face-to-face discussions" and that "consensus reached by the group reflects reasoned opinions" (p. 426), as people have not only had time to reflect on their own answers, but have the advantage of insight into others' opinions and selections. 
As with other research methods, the Delphi method has some limitations and disadvantages. These are discussed below, along with strategies used for minimizing these issues.

\section{Time consuming}

Delphi is time consuming for researchers and participants. The researcher needs to spend considerable time to design, distribute, analyse, and report back to the panel of experts, and then repeat the process at least once more. This was particularly problematic in the first Delphi studies that used pen and paper questionnaires, and relied on the postal system for delivery and return of those questionnaires. However, the advent of online surveys and email has greatly reduced the time between rounds.

Participants are required to commit to a series of data collection rounds over an extended period. The quality of their responses will depend not only on their level of expertise, but also the time available to provide thoughtful responses, potentially on three, four or more occasions. This time commitment is one of the main causes of dropout in Delphi studies. In order to minimize this aspect in the dissertation research, a detailed explanation of the process was sent to potential participants to make them aware of the requirements of this type of study, enabling them to make an informed decision prior to agreeing to participate in the study.

\section{Low response rate/dropouts}

Low response and high dropout rates are quite common. This is not unique to the Delphi method, but due to its iterative nature, the risk of dropout 
increases with each round. Again, the comprehensive explanation provided to participants assisted in this regard. Additionally, I was as succinct as possible when designing each questionnaire, so as to keep the process as focused as possible.

\section{Participant selection}

Problems can arise in the selection of participants around their standing, with regard to determining their status as expert. Claims of bias on behalf of the researcher have been made against this aspect of the Delphi method. In order to minimise such claims in this study, a set of criteria were created based on procedures established by Okoli and Pawlowski (2004). A detailed explanation of these criteria can be found in the "Selecting the panel of experts: Online questionnaire rounds" section below.

\section{Coding / interpretation of qualitative data}

It has been noted in the literature (Brewer, 2007) that it is possible for researchers to manipulate the direction of each of the Delphi rounds to fit with any pre-conceived notions that they may have. The interpretation and analysis of qualitative data is not a Delphi-specific problem, but an important consideration for qualitative research generally.

Despite these disadvantages, there were many advantages to using aspects of the Delphi method for the study. Hsu and Sandford (2010) note that "common surveys try to identify what is. The Delphi method attempts to assess what could or should be" (para. 1), a point that is reflected in the aim of the study, which was to identify the future education needs of information professionals who will work 
in the cultural heritage environment. They also suggest that it is a suitable method for collecting data "from experts on problems or issues for which no previously researched or documented information is available" (Hsu and Sandford, 2010, para. 14), a point on which Gupta and Clarke (1996) concur.

Although theory building is not its main focus, Delphi studies can nevertheless be beneficial in developing theory (Day and Bobeva, 2005; Okoli and Pawlowski, 2004), and this is further enhanced by incorporating aspects of grounded theory to form the GDM that was used in the study. Those aspects are discussed in the next section.

\section{Grounded theory}

Grounded theory is a methodology created by sociologists Barney Glaser and Anselm Strauss in the 1960s, specifically to guide theory building from qualitative data analysis (Päivärinta, Pekkola, and Moe, 2011). The intention is that a theory 'grounded' in the data emerges "without the researcher bringing his/her theoretical ideas and forcing a certain theory to emerge" (Päivärinta et al., 2011, p. 3). The definition that the creators themselves gave to grounded theory is that it is "the discovery of theory from data - systematically obtained and analysed in social research" (Glaser and Strauss, 1967, p. 1).

As with the Delphi method, the data collection and data analysis processes for grounded theory are closely intertwined and iterative. The initial analysis process is used to generate categories and is commenced as soon as the first set of data has been collected. Open coding using the constant comparison method is often used to generate these initial categories (Urquhart, Lehmann, and Myers, 
2010). The benefit of using the constant comparison method is that it "helps to ensure the categories and the resulting theory are properly grounded" (Urquhart et al., 2010, p. 377). Data collection continues until the identified categories are 'saturated' - that is, "well represented by many instances in the data" (Urquhart et al., 2010, p. 372).

One of the key capabilities that researchers must have or must develop in order to posit a theory at the end of their study is what is known as 'theoretical sensitivity' (Glaser, 1978; Oleson, 2007). This is the ability of a researcher to not only be able to define and describe categories, but to be able to see the relationships between these categories. This has been noted as being a challenge for inexperienced researchers (Päivärinta et al., 2011). The issue is further reinforced when the researcher is required to decide which categories are more important than others and which ones will form the basis of the new theory. The GDM incorporates elements of the Delphi method here to improve the theory building aspect, and this is discussed in the next section.

One of the criticisms often levelled at grounded theory is that despite the method being intended to develop theories, very few studies actually propose or identify a theory (Urquhart et al., 2010). This has led to the method being viewed as only a way of coding data. Different authors have suggested different guidelines as to what coding procedures should take place and when. For example, Glaser (1978) and Urquhart et al. (2010) suggest open coding, followed by selective coding, and then theoretical coding. Orlikowski (1993) follows the Strauss and Corbin (1990) steps of open, axial, and selective coding. The creators of the GDM explicitly state that they used the Straussian approach to grounded 
theory of open, axial, and selective coding (Päivärinta et al., 2011), so this was the approach I also followed.

\section{Grounded Delphi Method}

Both grounded theory and the Delphi method are methods used for exploratory research. However, the creators of the GDM saw shortcomings in both the Delphi method and grounded theory and sought to combine key elements of both, thus extending the scope of both methods.

As mentioned, although theory building is a possible outcome of using the Delphi method, according to Päivärinta et al. (2011) there are "few analytical tools $[\ldots]$ provided for this purpose" (Abstract). In order to go beyond the forecasting abilities inherent in a Delphi study and move towards theory building, Okoli and Pawlowski (2004) suggest that "the participating experts should justify their responses in order to facilitate the observation of causal relationships between the factors identified in the study" (as cited in Päivärinta et al., 2011, p.

2). Having an initial brainstorming round and asking participants to include "conditions for and consequences of the suggested issues" (Päivärinta et al., 2011, p. 10), yields richer data that is more receptive to theory building, rather than simply providing a list of challenges to be ranked in order to gain consensus. Specifically, the researcher can carry out the coding tasks that are central to grounded theory, allowing for the emergence of "core conceptual categories and their relationships" (Päivärinta et al., 2011, p. 2). By following grounded theory principles in the data analysis stages (open, axial, and selective coding), Päivärinta 
et al. (2011) suggest that the rigour of the theory building in Delphi can be increased.

As noted earlier, the need for theoretical sensitivity to be able to define categories and their relationships is a challenge for users of grounded theory. In order to move to the theory building stage, the researcher needs to decide which categories are more important than others. The creators of the GDM suggest that the consensus and/or 'force ranking' processes of the Delphi method were seen to be a useful addition to grounded theory to assist in deciding the relative importance of each category.

The GDM has been applied to one research project (Moe and Päivärinta, 2011) and one doctoral dissertation (Hussey, 2012) to date, in addition to the research being reported here. Hussey's (2012) dissertation used the GDM in order to understand the ways in which prayer integrated intuitive and logical decision-making for the Christian business leader. The research project - the first documented use of the GDM - dealt with the challenges associated with information technology procurement in the public sector in Norway (Moe and Päivärinta, 2011). Päivärinta et al., (2011) provide a detailed, step-by-step description of their method, gained not only by this single implementation of the GDM, but also by their previous experience with Delphi studies and grounded theory as separate methods.

\section{Research design: Application of the Grounded Delphi Method}

The application of the GDM as it was used in the GLAM dissertation research comprised three rounds of data collection: the first was exploratory focus 
groups, followed by two rounds of online questionnaires. Each round involved compiling, pilot testing and implementing a separate data collection instrument and then analysing the data. Data analysis for each round identified a set of categories that were incorporated into the next round's data collection instrument.

\section{Round 1: Exploratory focus groups}

The first round of the study was an exploratory focus group. As discussed above, this form of the Delphi method is suitable when very little literature exists on a given subject (Hsu and Sandford, 2010; Day and Bobeva, 2005). As there is very little empirical research done in the Australian cultural heritage field from the perspective of the dissertation, I employed this approach. It resembled a 'modified Delphi' (McKenna, 1994), as it was conducted using focus groups, rather than the more usual open-ended questionnaire (Keeney, Hasson and McKenna, 2011; Carnes, Mullinger and Underwood, 2010; Boendermaker et al., 2003).

In order to gain a deeper understanding of the four GLAM sectors, a separate focus group was held for each. This also ensured that the voice of each sector could be heard without fear of one sector dominating the other. I created a discussion guide informed by a combination of existing literature and the research questions. I used this discussion guide for each focus group, making no distinction between the GLAM sectors. This helped to ensure that each focus group explored similar issues.

Considerable care was taken in compiling the focus group questions to ensure that they were meaningful to participants whilst likely to prompt full and 
relevant responses. Collectively, the questions asked in each focus group, including the pilot, were designed to give me a better understanding of each sector, and to allow any similarities and/or differences amongst the sectors to emerge. This in turn informed the construction of the questionnaire for the next round of data collection.

\section{Participant selection: Exploratory focus groups}

The participants for both the first round exploratory focus groups and the pilot study were sought from my professional network, followed by a sampling technique known as snowball sampling, whereby an existing participant recommends other potential participants. At this early stage of the research, and because of the exploratory nature, strict criteria regarding the participants' expert status were not imposed on the participants, as is often the case in a Delphi study. There were several reasons for this:

1. As this first round was exploratory, I did not want to exclude anyone from contributing.

2. Logistically, as the focus groups were to be held in person, this inevitably limited who could be included.

3. By not imposing criteria at this stage, a better sense of what the criteria could be evolved.

\section{Rounds 2 and 3: Online questionnaire}

Despite concerns about online participants being "less likely to explain their opinions" (Schneider, Kerwin, Frechling, and Vivari, 2002, p. 39), this was 
not deemed to be problematic for the online questionnaires. Firstly, although the research was still deemed to be 'exploratory' in nature, the questionnaires would be exploring the themes generated by the focus groups. Secondly, wherever possible, I included free-text comments boxes within the questionnaire, and specifically asked participants to elaborate on their response.

Moving from the exploratory focus groups in Round 1 to the questionnaire Rounds 2 and 3 required a significant amount of preparation, particularly in relation to selecting the panel of experts to participate, the development of the questionnaires themselves and setting the consensus level in order to conform to this component of a Delphi study. The following sections discuss the process of selecting a panel of experts and setting the 'a priori' consensus level.

\section{Selecting the panel of experts: Online questionnaire rounds}

As mentioned earlier, selecting the panel of experts is one of the most important aspects of the Delphi method. Paradoxically, however, the definition of what constitutes an "expert" in relation to a Delphi study has remained ambiguous, with the literature providing very little guidance or criteria in this area (Hsu and Sandford, 2007; Judd, 1972). Whilst not providing a definition of an expert, Okoli and Pawlowski (2004) do provide quite detailed procedures for selecting experts. As Moe and Päivärinta (2011) and Päivärinta et al. (2011) employed these procedures in their Grounded Delphi study, it was appropriate to use them for this research.

The first step that Okoli and Pawlowski (2004) use in identifying experts is to prepare a Knowledge Resource Nomination Worksheet (KRNW). This enables 
the researcher to "help categorize the experts before identifying them" (Okoli and Pawlowski, 2004, p. 20). Additionally, it could be considered that this also assists in reducing bias, as the researcher is not merely selecting known associates in familiar disciplines or organisations.

The KRNW consists of three categories from which potential experts may be drawn: Disciplines, Organisations and Literature. 'Disciplines' does not necessarily refer to academic disciplines such as Engineering or Arts, but rather areas or sectors where potential experts may be located, for example 'public sector' or 'not-for-profit' organisations. The Organisations category refers to specific organisations where experts may be found, for example, the United Nations and the World Health Organisation. The final category, Literature, is used to help identify areas where experts may have published. Again, this is not specifically limited to academic literature, although in many instances (including this research), this was the case.

The second step of the KRNW is "to populate the categories with actual names of potential experts" (Okoli and Pawlowski, 2004, p. 20) starting with personal contacts. In this way, I identified approximately ten people across all four GLAM sectors. While I acknowledge that selecting participants from personal contacts introduces a level of bias, as discussed above, of the ten identified in this second step of the KRNW, I considered only one to be a close contact. The remaining nine included Round 1 focus group participants, with whom I had maintained a professional level of contact through conference attendance, email and Twitter. 
I added one final criterion to Okoli and Pawlowski’s (2004) process for identifying experts. This was as a result of both the focus groups and informal interviews and conversations I had with various professionals: the people who seemed to fully understand the essence this research - and its potential significance - often had experience of at least two of the GLAM sectors. This usually took the form of either a combination of qualifications and workplace experience, for example having library qualifications but working in a museum; or having worked in two (or more) of the sectors.

After completing all four steps of the KRNW process, a total of 108 potential participants were identified. In order to be able to refine this number into a manageable cohort to participate in the questionnaire rounds, each potential participant was mapped against the four criteria just discussed. Rather than expecting each participant to meet every criterion, I decided that the sector pool as a whole should be representative of all criteria requirements. Further, if potential participants were ranked in terms of the number of criteria they met, there was the possibility that one criterion may not be represented at all in one or more of the sector pools.

As there is no clear consensus in the literature about the ideal number of participants for a successful Delphi study, it comes down to the researcher's discretion to make an informed decision. I decided to include ten participants from each of the four GLAM sectors, making a total of forty participants. Although this is in excess of the maximum 25-30 suggested by Delbecq et al., (1975) and Brooks (1979, as cited in Murry and Hammons, 1995), all four sectors 
of GLAM needed reasonable representation, and it was preferable to determine the numbers on the individual sectors rather than the overall total.

As previously highlighted, one of the potential disadvantages of the iterative element of a Delphi study is the participants dropping out between rounds. To minimise this, the email I sent requesting participation included detailed information about this aspect of the process. This approach is supported by Pollard and Pollard (2004). Although difficult to advise with any certainty, the number of rounds and the anticipated time frames of those rounds were included in the email as an indication to allow people to make an informed decision as to whether the request could be accommodated within their schedule. In keeping with Delphi and Grounded Delphi procedures, the participants remained the same for each of the online questionnaire rounds.

\section{Setting the a priori consensus level}

As with a number of other aspects of the Delphi method that are incorporated into the GDM, there are no set criteria to determine what constitutes consensus. In a comprehensive literature review, Heiko (2012) examined 15 types of consensus measurement, one of which is defining a level of agreement prior to the data collection rounds. This level "can be based on accepted standards, such as political voting systems (e.g. simple majority, two-thirds majority, absolute majority)" (Heiko, 2012, p. 1530). Based on this, I determined that a three-quarters majority - or $75 \%$ consensus - would be acceptable. 


\section{Data analysis: Incorporating grounded theory coding procedures}

\section{Open coding}

The initial stage of data analysis in grounded theory is open coding, so named because according to Strauss and Corbin (1990), it is the process of 'opening up' the text of the collected qualitative data to identify ideas, themes or meanings (Benaquisto, 2008a). The constant comparative method was used, and while at this stage it is recommended to code at the sentence and/or word level, it is not forbidden to code at a higher level, as the level of coding applied may depend on the context of study. The reasoning behind coding at such a low level is that aside from the insights it offers, it produces a "chain of evidence" (Urquhart et al. 2010, p. 369) from data to theory. This is a quality inherent in the grounded theory method.

\section{Axial coding}

Axial coding was the analysis process undertaken once all the categories have been identified by the initial open coding phase. It involved refining and developing individual categories, which included documenting the characteristics of each category (Benaquisto, 2008b). Once this was done, relationships between categories were identified, which involved merging of similar categories, renaming them and broadening the scope.

\section{Selective coding}

Once the categories were identified through open coding, and relationships between them identified through axial coding, selective coding took place. 
Benaquisto (2008c) describes selective coding as the process where a researcher identifies and selects a 'core' category from the existing categories. The core category becomes "the central category that represents the major theme or "essence" of the research (Benaquisto, 2008c, p. 806), and the remaining major categories are then related to the core category. I then set about explaining not only the relationship between the categories, but also the nature of those categories - what they mean, and the significance of them.

\section{Evaluation of the method and implications for Library and Information}

\section{Science (LIS)}

Implications of using the GDM for LIS research, and for research methods in general, is that it takes two established methods - both with documented shortcomings - and proposes a third method using aspects of both, which seeks to minimise those shortcomings. The GDM improves the rigour of theory building in Delphi studies by incorporating elements of grounded theory in both the data collection and data analysis phases. The consensus, or force ranking, aspect of the Delphi method assists in improving the relevant level of importance of categories derived from grounded theory.

For the most part, the dissertation research followed the process established by the creators of the GDM, Päivärinta et al. (2011). The major point of departure was in the selective coding phase. Päivärinta et al. (2011) used the ranking procedure in order to determine which were the most important challenges, whereas the aim of the current study was an understanding of what is needed for the future education requirements of information professionals who 
will work in the GLAM sector. As such, the process followed in the current study may be viewed as an alternative to the ranking procedure, enhancing the GDM by offering a level of flexibility.

The creators of the GDM, Päivärinta et al., also state that the GDM "is recommended for exploratory research in emerging research areas" (2011, Abstract). In an ever changing and developing discipline that is LIS, this makes it a highly appropriate method for a variety of potential applications.

Although a fully developed theory did not emerge from this study, the beginnings of theoretical constructs regarding both ontological and epistemological dimensions required in an educational framework for GLAM professionals were cultivated. This can largely be attributed to the GDM itself, in particular the coding aspects derived from grounded theory. The emerging constructs are potentially more rigorous than those that may have developed in a pure grounded theory study due to the consensus elements of Delphi, and the requirement that all research participants should be considered experts. In the current study, the use of the KRNW to select the panel of experts (as discussed in the "Selecting the panel of experts: Online questionnaire rounds" section) assists in supporting their expert status, and offers a somewhat improved level of transparency, thus reducing potential bias.

While considerable effort was required to conduct research using the Grounded Delphi Method, on reflection, this is not in excess of the effort that would be required to conduct a standard Delphi study. The major advantage is having the grounded theory coding techniques to guide the data analysis, as prior to the development of the GDM, no such instructions existed in any Delphi 
method guides. Coupled with the increased rigour of any developed theory, I believe the use of the GDM was an extremely effective method for the research undertaken.

\section{Conclusion}

This paper has described a relatively new methodology, the Grounded Delphi Method, which has its origins in both Delphi and grounded theory methodologies. The application of the GDM method to the current research is only the third documented occurrence, and contributes to qualitative research methodology by further developing the Grounded Delphi Method and establishing it as a viable alternative to the standard Delphi or grounded theory methods.

\section{References}

Benaquisto, L. (2008a). Open Coding. In L.M. Given (Ed.), The SAGE Encyclopedia of Qualitative Research Methods (pp. 582-583). Thousand Oaks, CA: SAGE Publications, Inc.

Benaquisto, L. (2008b). Axial Coding. In L.M. Given (Ed.), The SAGE Encyclopedia of Qualitative Research Methods (pp. 52-53). Thousand Oaks, CA: SAGE Publications, Inc.

Benaquisto, L. (2008c). Selective Coding. In L.M. Given (Ed.), The SAGE Encyclopedia of Qualitative Research Methods (pp. 806-807). Thousand Oaks, CA: SAGE Publications, Inc. 
Boendermaker, P.M., Conradi, M.H., Schuling, J., Meyboom-De Jong, B., Zwierstra, R.P., \& Metz, J.C. (2003). Core characteristics of the competent general practice trainer, a Delphi study. Advances in Health Sciences Education: Theory and Practice, 8, 111-116.

Brewer, E. (2007). Delphi Technique. In N.J. Salkind \& K. Rasmussen (Eds.), Encyclopedia of Measurement and Statistics (pp. 240-246). Thousand Oaks, CA: Sage Publications, Inc.

Carnes, D., Mullinger, B., \& Underwood, M. (2010). Defining adverse events in manual therapies: a modified Delphi consensus study. Manual therapy, 15(1), 2-6.

Charlton, J. (2003). Delphi Technique. In M.S. Lewis-Beck, A. Bryman, \& T.F. Liao (Eds.), The SAGE Encyclopedia of Social Science Research Method (pp. 244-245). Thousand Oaks, CA: Sage Publications, Inc.

Dalkey, N., \& Helmer, O. (1963). An Experimental Application of the Delphi Method to the Use of Experts. Management Science [online], 9(3), 458467. Retrieved from http://www.jstor.org/stable/2627117

Day, J., \& Bobeva, M. (2005). A Generic Toolkit for the Successful Management of Delphi Studies. The Electronic Journal of Business Research Methodology, 3(2), 103-116. Retrieved from http://www.ejbrm.com/main.html

Delbecq, A.L., Van de Ven, A.H., \& Gustafson, D.H. (1975). Group technique for program planning: A guide to nominal group and Delphi processes. Glenview, IL: Scott, Foresman and Co. 
Forsyth, D. (2009). Delphi technique. In J. Levine \& M. Hogg (Eds.), Encyclopedia of group processes and intergroup relations (pp. 195-197). Thousand Oaks, CA: SAGE Publications, Inc.

Glaser, B.G. (1978). Theoretical Sensitivity: Advances in the Methodology of grounded theory. Mill Valley, CA: The Sociology Press.

Glaser, B.G., \& Strauss, A.L. (1967). The Discovery of grounded theory: Strategies for Qualitative Research. Chicago, IL: Aldine Publishing Company.

Gottschalk, P. (2000). Studies of key issues in IS management around the world. International Journal of Information Management, 20(3). doi: $10.1016 / \mathrm{S} 0268-4012(00) 00003-7$

Gupta, U.G., \& Clarke, R.E. (1996). Theory and Applications of the Delphi Technique: A Bibliography (1975-1994). Technological Forecasting and Social Change, 53, 185-211.

Heiko, A. (2012). Consensus measurement in Delphi studies: review and implications for future quality assurance. Technological Forecasting and Social Change, 79(8), 1525-1536.

Hsu, C., \& Sandford, B. (2007). Delphi technique: Making sense of consensus. Practical Assessment Research Evaluation, 12(10). Retrieved from http://pareonline.net/pdf/v12n10.pdf

Hurworth, R. (2004). Delphi Technique. In S. Mathison (Ed.), Encyclopedia of Evaluation (pp. 108-109). Thousand Oaks, CA: SAGE Publications Inc. 
Hussey, D. S. (2012). In what ways does prayer create integration between intuitive and logical decision making processes for the Christian business leader? A Grounded Delphi Method exploration. Ann Arbor, MI: UMI Dissertation Publishing.

Judd, R. (1972). Use of Delphi methods in higher education. Technological Forecasting and Social Change, 4(2), 173-186.

Keeney, S., Hasson, F., \& McKenna, H. (2006). Consulting the oracle: Ten lessons from using the Delphi technique in nursing research. Journal of Advanced Nursing, 53(2), 205-212.

Linstone, H.A., \& Turoff, M. (Eds.). (1975). The Delphi Method: Techniques and Applications. Reading, MA: Addison-Wesley Publishing Company.

McKenna, H. P. (1994). The Delphi technique: a worthwhile research approach for nursing? Journal of advanced nursing, 19(6), 1221-1225.

Moe, C.E., \& Päivärinta, T. (2011). Challenges in Information Systems Procurement in the Norwegian Public Sector, In M. Jenson, H. Scholl, M. Wimmer, \& Y. Tan (Eds.), EGOV 2011, LNCS 6846 (pp. 404-417). Berlin, Germany: Springer.

Murry Jr, J.W., \& Hammons, J.O. (1995). Delphi: A versatile methodology for conducting qualitative research. The Review of Higher Education, 18(4), 423-436.

Okoli, C., \& Pawlowski, S.D. (2004). The Delphi method as a research tool: an example, design considerations and applications. Information and Management 42(1), 15-29. 
Olesen, V.L. (2007). Feminist Qualitative Research and grounded theory: Complexities, Criticisms, and Opportunities. In A. Bryant \& K. Charmaz (Eds.), The SAGE Handbook of grounded theory. London, England: SAGE Publications Ltd.

Orlikowski, W. J. (1993). CASE tools as organizational change: Investigating incremental and radical changes in systems development. MIS Quarterly, 17(3), 309.

Päivärinta, T., Pekkola, S., \& Moe, C. (2011). Grounding Theory from Delphi Studies. ICIS 2011 Proceedings, Paper 4. Retrieved from http://aisel.aisnet.org/icis2011/proceedings/researchmethods/4/

RAND Corporation. (2012). Delphi Method. Retrieved from http://www.rand.org/topics/delphi-method.html

Rowe, G., Wright, G., \& Bolger, F. (1991). Delphi: A re-evaluation of research and theory. Technological Forecasting and Social Change, 39(3), 235251.

Schneider, S. J., Kerwin, J., Frechtling, J., \& Vivari, B. A. (2002). Characteristics of the discussion in online and face-to-face focus groups. Social science computer review, 20(1), 31-42.

Strauss, A., \& Corbin, J. (1990). Basics of Qualitative Research: grounded theory Procedures and Techniques. Newbury Park, CA: Sage Publications.

Urquhart, C., Lehmann, H., \& Myers, M.D. (2010). Putting the 'theory' back into grounded theory: guidelines for grounded theory studies in information systems. Information Systems Journal, 20, 357-381. 


\section{The Occasion}

This paper is based on the Methodology chapter of the author's $\mathrm{PhD}$ thesis completed at the Queensland University of Technology, 2015. The thesis can be freely downloaded at https://eprints.qut.edu.au/85088/

\section{Acknowledgement}

This research was supported financially by an Australian Postgraduate Award (APA) Scholarship. The author gratefully acknowledges the financial assistance provided by a Eugene Garfield Doctoral Dissertation Fellowship from Beta Phi $\mathrm{Mu}$; and the guidance provided by her Supervisory team: Prof. Helen Partridge, A/Prof. Hilary Hughes and A/Prof. Gillian Oliver.

The author would also like to thank the reviewers for their suggestions for improvements to this paper.

\section{Open access and copyright}

Library and Information Research is an open access journal. A freely available copy of this paper may be downloaded from the journal's website:

http://www.lirgjournal.org.uk

Copyright and associated moral rights in works published in Library and Information Research are retained by the author(s) but this paper may be used freely, with proper attribution, in educational and other non-commercial settings. 